\title{
Use of social media in education among medical students in Saudi Arabia
}

\author{
Anas Khaleel Alsuraihi', Ahmed Saeed Almaqati', Sultan Adnan Abughanim ${ }^{1}$ \\ and Nisreen Abdulrahman Jastaniah ${ }^{2}$
}

${ }^{1}$ King Abdullah International Medical Research Center/King Saud bin Abdulaziz University for Health Sciences College of Medicine, Ministry of National Guard Health Affairs, and ${ }^{2}$ King Abdullah International Medical Research Center/King Saud bin Abdulaziz University for Health Sciences, Family Medicine, Geriatric and Palliative Care, Ministry of National Guard Health Affairs, Jeddah, Saudi Arabia

Purpose: Social media (SM), a virtual place where people can share, exchange, and communicate their ideas and knowledge, has become the new trend in communication and learning. This study aims to explore Saudi Arabian medical students' usage of SM and to discover the most common resources used in medical education. Furthermore, it aims to illustrate students' belief about the influence of SM on their learning.

Methods: This cross-sectional study administered validated questionnaires to medical students from different universities in Saudi Arabia, via emails, Twitter, Facebook, and short message service. A non-probability sampling technique was utilized and a sample size of 381 students was arrived at, using 95\% confidence interval and $5 \%$ margin of error, since the total number of medical students in Saudi Arabia is approximately 36,000. The total respondents were 657 students from 23 different Saudi Arabian medical schools (females: $60.5 \%, n=397$; males: $39.5 \%, n=260$ ).

Results: The questionnaires of $21 \%$ of the students $(n=139)$ were excluded from the analysis since they were incomplete. The most common website used by both genders was YouTube $(42.3 \%, n=185)$; however, males preferred using Twitter and Wikis $(p=0.001)$. With regard to utilizing SM for learning, 95.8\% $(n=419)$ of the students believed that it is beneficial. Females stated that SM helps them link basic and clinical science $(p=0.003)$.

Conclusion: Medical schools need to improve the utilization of SM by their faculty and students by developing activities and encouraging the usage of SM in education.

Key Words: Medical education, Social media

\section{Introduction}

One of the most powerful communication tools of the 21st century is social media (SM). SM includes web tools and applications designed to facilitate online interaction and instant information sharing. Social network users interact through sharing texts, photos, and audio and video messages [1]. The role of SM is varied: it helps people communicate with each other, advocate about topics of concern, and share their common interests, as well as gives them the freedom to express their emotions and opinions. For instance, patients commonly use websites such as Facebook, MySpace, and YouTube to share
Received: March 15, 2016 • Revised: May 26, 2016 • Accepted: July 6, 2016 Corresponding Author: Anas Khaleel Alsuraihi (http://orcid.org/0000-0002-7803-2737) King Saud bin Abdulaziz University for Health Sciences College of Medicine, King Abdulaziz Medical City, P.O.Box 9515, Jeddah 21423, Saudi Arabia

Tel: +966-12-2266666 Fax: +966-12-2266200 email: Anas.k.s@hotmail.com
Korean J Med Educ 2016 Dec; 28(4): 343-354.

https://doi.org/10.3946/kjme.2016.40

eISSN: 2005-7288

(C) The Korean Society of Medical Education. All rights reserved. This is an open-access article distributed under the terms of the Creative Commons Attribution Non-Commercial License (http:// creativecommons.org/licenses/by-nc/3.0/), which permits unrestricted non-commercial use, distribution, and reproduction in any medium, provided the original work is properly cited. 
personal information about their diseases [2]. It is used for educational purposes in various fields, such as pharmacy. Tutors can use social networks to increase their chances of success in student recruiting and brand management [3]. Recently, SM usage in medical education has been gradually increasing. For example, 132 of all U.S. medical schools have a website and $95 \%$ of them have some Facebook presence. Out of these schools, 26\% have official medical school SM pages and $71 \%$ have student groups [4].

The use of SM by medical students has become a very popular method to engage teachers and learners [5]. According to social-constructivist principles of Dewey and Vygotsky [6], social interaction, sharing of information and active participation in SM activities may facilitate learning. A recent pilot study evaluated the integration of Twitter, YouTube, Flicker, Blogging, and Skype in two elective courses for fourth year medical students at the Penn State College of Medicine [7]. The results of this study showed that students were satisfied by the new approach in both courses. They also expressed the extent to which the integration of SM in teaching enhanced their learning. However, some students reported challenges such as lack of time and technological facilities [7]. Since the introduction of the Internet in Saudi Arabia in 1994 for academic, medical, and research institutions' usage, there have been limited studies about the effect of using SM on medical students' learning, despite the dramatic increase in the number of medical schools [8]. In addition, students' awareness and the need for a SM usage policy is of important concern since it allows them to communicate with their tutors without any restriction. A cross-sectional study among medical students in Qassim University showed that $80 \%$ of the students used computers for academic purposes [9]. A recent systematic review showed that SM promotes student engagement and enhances deeper understanding; however, one of the obstacles to this was privacy issues, as reported by $29 \%$ of the participants [10].

This study was conducted to produce measurable statistical data on Saudi Arabian medical students' SM usage, since sufficient data to examine the relationship between SM and medical education is unavailable.

This study aims to explore Saudi Arabian medical students' SM usage and to discover the most common resources used in medical education. Furthermore, it aims to illustrate students' belief about the influence of SM on their learning.

\section{Subjects and methods}

This cross-sectional analytical study was approved by the Institutional Review Board. An online questionnaire was distributed to medical students from different grades and universities in Saudi Arabia, from June 1 to August 30, 2013, via emails, Twitter, Facebook, and short message service. According to the Ministry of Higher Education, the total number of medical students in all universities is around 36,000. We utilized a nonprobability sampling technique, and the sample size was calculated using 95\% confidence interval and 5\% margin of error; we needed to include 381 participants. To compensate for the expected incomplete questionnaires, we decided to include a total of 400 participants. The questionnaires were distributed through SM along with an invitation cover letter. All respondents were included in the study, except the ones who are interns and those who are studying abroad.

Participants were invited to voluntarily and anonymously complete a validated questionnaire. The questionnaire was piloted for face/content validity by distributing it to 10 medical students from different grades, 
and was then peer reviewed by two assessors who examined its psychometric characteristics (Appendix 2). It consisted of four main parts: the student's demographic and personal data (age, gender, year of study, and school name); SM details (usage of SM, frequency, type of SM, and preferred platform); belief about SM's influence on learning (influence on education, communication, and collaboration); and barriers and challenges for using SM in education (ethical barriers, institutional availability, and cooperation). A Likert-type scale was used in sections 2, 3, and 4 of the questionnaire (where $1=$ strongly disagree, $2=$ disagree, $3=$ =undecided, 4=agree, and $5=$ strongly agree).

We classified the students into three categories: premedical, medical, and clinical phases. Most Saudi Arabian universities offer a 6-year medical program, wherein students study basic sciences, such as physics, chemistry, and biology, in their first 2 years (premedical phase); medical sciences, such as anatomy, physiology, and pharmacology, during the next 2 years (medical phase); and a specialty in rotation with others, such as medicine, surgery, and pediatrics, in the last 2 years (clinical phase).

We conducted a reliability analysis and evaluated the item-total correlation matrix. The average item-total correlation was above 0.3 , and the standardized Cronbach's $\alpha$ was above 0.65 .

SurveyMonkey designed the survey and collected the data. SPSS version 21.0 (IBM Corp., Armonk, USA) was used for the data analysis. Descriptive statistics were utilized for mean scores and proportions. Skewed data were transformed to normal distribution ones using logtransformation methods, and parametric statistical methods were utilized. The correlation matrix was used to analyze the item-total correlation. Independent sample Student $t$-test and multiple linear regression were utilized to measure the significance of associations between dependent and independent variables. All tests were two-tailed, and $\mathrm{p}$-value of $<0.05$ was considered significant.

Table 1. Demographic Details of Participants

\begin{tabular}{|c|c|}
\hline Characteristic & №. $1 \% 1$ \\
\hline \multicolumn{2}{|l|}{ Gender } \\
\hline Male & $260(39.5)$ \\
\hline Female & $397(60.5)$ \\
\hline \multicolumn{2}{|l|}{ Medical year } \\
\hline Premedical phase & $74(11.26)$ \\
\hline Second year & 108 (16.44) \\
\hline Medical phase & $143(21.77)$ \\
\hline Fourth year & 105 (15.98) \\
\hline Clinical phase & $100(15.22)$ \\
\hline Sixth year & 127 (19.33) \\
\hline \multicolumn{2}{|l|}{ Name of university } \\
\hline Umm Al-Qura University & $176(26.8)$ \\
\hline King Abdulaziz University & $152(23.2)$ \\
\hline King Saud bin Abdulaziz University for Health Sciences & $68(10.4)$ \\
\hline King Saud University & $44(6.7)$ \\
\hline Others ${ }^{\text {al }}$ & $217(32.8)$ \\
\hline
\end{tabular}

${ }^{a l} N B U, T U, K F U, U T$, QU, KKU, JU, PNU, IMAM U, TAIBAH U, DMU, ISNC, SAU, UNAIZAUM, BU, ALFAISAL U, MCST, UOH, and BMC (names indexed in Appendix 1). 


\section{Results}

The total number of respondents was 657 students from 23 different Saudi Arabian medical schools. The respondents were mostly from Umm Al-Qura University (26.8\%, $\mathrm{n}=176)$, followed by King Abdulaziz University $(23.2 \%, n=152)$. Females represented $60.5 \%(n=397)$ of the total participants. Majority of participants belonged to the medical phase $(37.8 \%, \mathrm{n}=248)$ (Table 1$)$.

Of the total participants, $87.7 \%(n=576)$ use $\mathrm{SM}$ in their education. However, this question was the endpoint for those who do not use SM in their education, and therefore 81 participants were initially excluded from the final analysis. Furthermore, 139 participants were excluded because they did not complete the questionnaire. Therefore, the total number of participants included in the final analysis was 437. Fig. 1 illustrates students' frequency of SM usage in learning.

There was no significant difference between genders in the frequency of using SM ( $\mathrm{p}=0.12)$. YouTube, Facebook, and Twitter were among the most commonly used resources, while the most common website used by both genders was YouTube $(42.3 \%, \mathrm{n}=185)$. However, males

Fig. 1. Frequency of Social Media Usage in Learning $(n=437)$

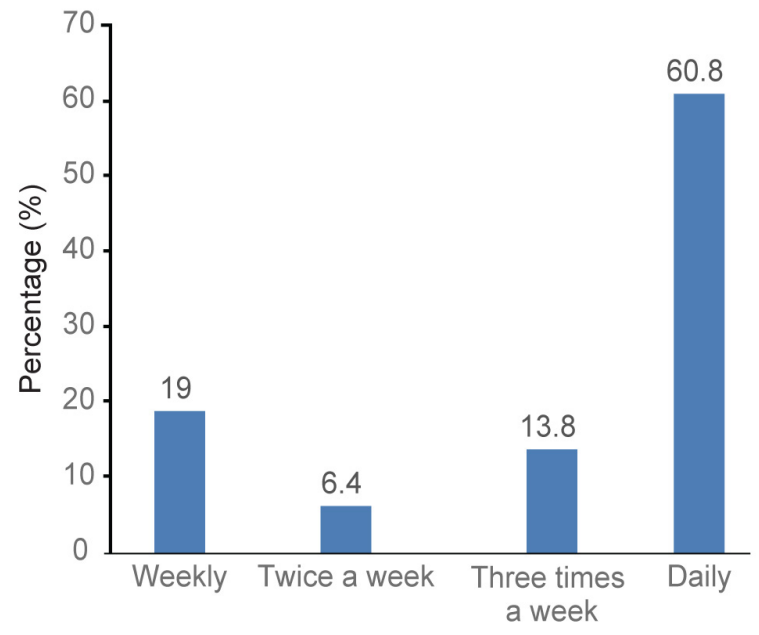

preferred using Twitter and Wikis ( $\mathrm{p}=0.001)$ (Figs. 2, 3). Regarding utilizing SM for learning, 95.8\% ( $\mathrm{n}=419)$ of the students believed that it is beneficial, while $40 \%$ ( $\mathrm{n}=175$ ) thought using SM might be distracting. There was no statistical significance between genders in the belief that using SM as an educational tool is beneficial. Compared to male students, females communicate more with their tutors through SM ( $\mathrm{p}=0.04)$.

Of all students, $74.4 \%(n=325)$ reported that their medical institution utilized SM in education. We found

Fig. 2. Social Media Resources Used in Medical Education $(n=437)$

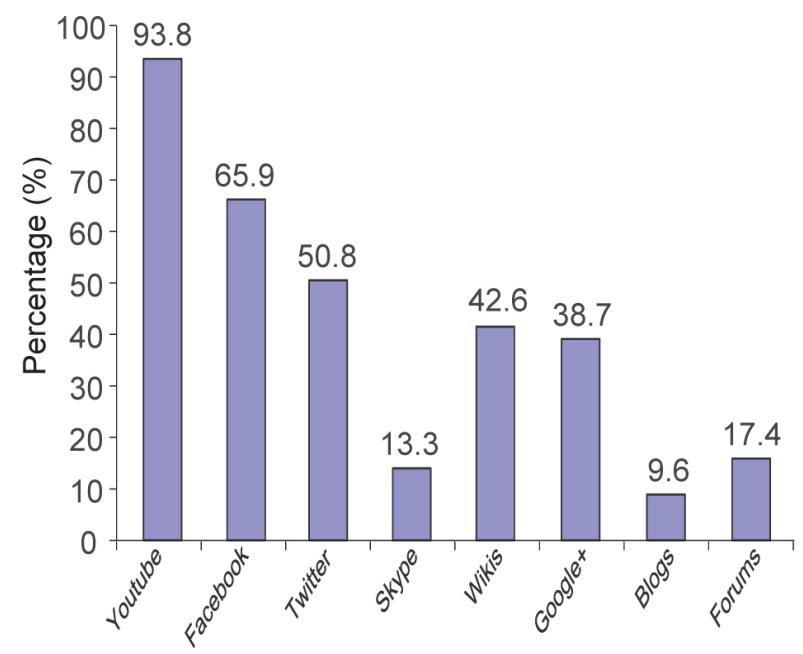

This question was a multiple answer question.

Fig. 3. Commonly Used Resources in Education $(n=437)$

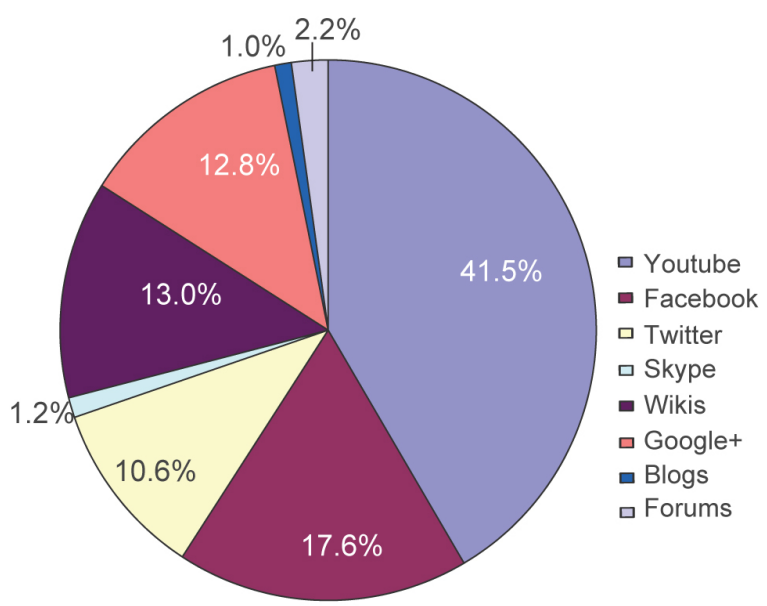


that clinical year students think that their tutors do not use SM effectively $(\mathrm{p}<0.01)$. SM facilitates communication among students with their peers in the same college, as well as those from other universities, especially among females ( $\mathrm{p}=0.001)$. SM was also found to help the students have a deeper understanding of a topic and link basic and clinical science. A majority of female students stated that SM helped them focus on important topics while studying for their exams $(\mathrm{p}=0.007)$. Hitherto, we have not been able to find any ethical guidance on using SM in medical education in Saudi Arabia, although a majority of participants $(72.7 \%, \mathrm{n}=318)$ think it is important to have one.

\section{Discussion}

This study showed that SM is commonly used in learning by medical students in Saudi Arabia. Of all participants, $87.7 \%$ ( $n=576)$ stated that they use SM in their education. However, our data showed no significant statistical gender difference similar to Avci et al.'s study [11]. We found that YouTube is the most used website (93.8\%) followed by Facebook (65.9\%), which does not match with the results of Barlow et al.'s study (Facebook, 99.4\%; YouTube, 96.9\%) [12]. On YouTube, it is easier to search for specific topics, to share it with others without the need for an account, and to find a variety of examples on the same subject. Moreover, YouTube was found to be better regarding content, integration of information, and interaction among users when compared to textbooks and eMedicine articles, as stated by Azer [13].

Since YouTube contains a large amount of educational materials that can be of low quality and not based on solid evidence, Assadi and Gasparyan [14] suggested the idea of creating a specialized platform for educational materials and discussions that are reviewed by health professionals. Creating such a website would need the presence of guidelines for posting educational materials, including ethical terms (confidentiality and respect of patient rights).

The spread of SM in Saudi Arabia has not been studied well; however, a Saudi social media agency acknowledged a growing use of it in recent years [15]. Surprisingly, more males than females preferred using Twitter and Wikis. We could not interpret the cause for this, and therefore further research is needed to explore this result.

A majority of students considered SM as beneficial to their learning, resembling the results of Avci et al.'s study. In a study that evaluated Twitter as a teaching tool, it was found that students believed it to be efficient and effective to their learning. It also strengthened student-tutor relationship [11,16].

Most students in our study think their tutors do not use SM effectively. This could be attributed to the absence of organizational policies or the underestimation of SM's importance in education. Therefore, more regional studies on the topic are required, since many international studies already exist in this area $[17,18]$.

Ethical guidance is rules and policies that guide and maintain the professional use of SM by defining what is forbidden and inappropriate [19,20]. Many countries have released policies regarding the professional use of SM, such as the American Medical Association policy [20]; however, similar ethical guidelines for SM usage in Saudi Arabia are absent.

The use of SM among students in medical education is common, and therefore medical schools need to improve the utilization of SM by their faculty and students by developing activities and encouraging the usage of SM in education. Medical institutions should also guide students on how to get the maximum benefit from SM and 
how to avoid its drawbacks, such as distractibility.

We recommend educational organizations to orient their tutors about the importance of SM, since we believe it saves time and simplifies instant group interaction. Further, we suggest that they create authentic SM pages on common resources, such as YouTube and Twitter, to supply students with reliable information. The presence of policies to guide the usage of SM is crucial to deliver valuable information, to maintain a professional atmosphere, and to ensure privacy.

One of the limitations of this study is that we used SurveyMonkey to collect data. Therefore, we could not calculate the response rate. Another limitation is that a large number of students did not complete the questionnaire $(21 \%, \mathrm{n}=139)$ and were hence excluded from the analysis.

\section{ORCID:}

Anas Khaleel Alsuraihi: http://orcid.org/0000-0002-7803-2737; Ahmed Saeed Almaqati: http://orcid.org/0000-0002-0557-0219; Sultan Adnan Abughanim: http://orcid.org/0000-0001-9856-6069; Nisreen Abdulrahman Jastaniah: http://orcid.org/0000-0003-4917-5381

Acknowledgements: We are deeply grateful to Dr. Basim Alsaywid, pediatric urology consultant, Department of Surgery, King Abdulaziz Medical City, Jeddah, Saudi Arabia, for his contribution to the data analysis and for his critical review of our study.

Funding: None.

Conflicts of interest: None.

\section{References}

1. Sarasohn-Kahn J. The wisdom of patients: health care meets online social media [Internet]. California Health Care Foundation; 2008 [cited 2013 June 20]. Available from: http://www.chcf.org/topics/chronicdisease/index.cfm? item $\mathrm{ID}=133631$.

2. Househ M. Sharing sensitive personal health information through Facebook: the unintended consequences. Stud Health Technol Inform 2011; 169: 616-620.

3. Cain J, Fox BI. Web 2.0 and pharmacy education. Am J Pharm Educ 2009; 73: 120.

4. Kind T, Genrich G, Sodhi A, Chretien KC. Social media policies at US medical schools. Med Educ Online 2010; 15.

5. Saarinen C, Arora V, Ferguson B, Chretien K. Incorporating social media into medical education [Internet]. Alliance for Academic Internal Medicine; c2011 [cited 2013 June 20]. Available from: http://www.im.org/p/cm $\mathrm{ld} / \mathrm{fid}=1017$.

6. Huang HM. Toward constructivism for adult learners in online learning environments. Br J Educ Technol 2002; 33: 27-37.

7. George D, Dellasega C. Social media in medical education: two innovative pilot studies. Med Educ 2011; 45: 1158-1159.

8. Internet in Saudi Arabia [Internet]. Communications and Information Technology Commission; c2011 [cited 2013 December 24]. Available from: http://www.internet.sa/ ar/internet-in-saudi-arabia/\#more-98.

9. Aldebasi YH, Ahmed MI. Computer and Internet utilization among the medical students in Qassim University, Saudi Arabia. J Clin Diagn Res 2013; 7: 1105-1108.

10. Cheston CC, Flickinger TE, Chisolm MS. Social media use in medical education: a systematic review. Acad Med 2013; 88: 893-901.

11. Avcı K, Çelikden SG, Eren S, Aydenizöz D. Assessment of medical students' attitudes on social media use in medicine: a cross-sectional study. BMC Med Educ 2015; 15: 18 .

12. Barlow CJ, Morrison S, Stephens HO, Jenkins E, Bailey MJ, Pilcher D. Unprofessional behaviour on social media 
by medical students. Med J Aust 2015; 203: 439.

13. Azer SA. Is Wikipedia a reliable learning resource for medical students? Evaluating respiratory topics. Adv Physiol Educ 2015; 39: 5-14.

14. Assadi R, Gasparyan AY. Editing, publishing and aggregating video articles: do we need a scholarly approach? J Korean Med Sci 2015; 30: 1211-1212.

15. The state of social media in Saudi Arabia vol 3 [Internet]. The Social Clinic \& The Loft Creative Hub; 2015 [cited 2016 May 11]. Available from: http://www. thesocialclinic.com/the-state-of-social-media-in-saudi-arab ia-vol-3/.

16. Paul S, Pusic M, Gillespie C. Medical student lecture attendance versus iTunes U. Med Educ 2015; 49: 530-531.
17. Chen B, Bryer T. Investigating instructional strategies for using social media in formal and informal learning. Int Rev Res Open Distance Learn 2012; 13: 87-104.

18. Moran M, Seaman J, Tinti-Kane H. Teaching, learning, and sharing: how today's higher education faculty use social media. Boston, USA: Pearson Learning Solutions; 2011.

19. Mansfield SJ, Morrison SG, Stephens HO, Bonning MA, Wang SH, Withers AH, Olver RC, Perry AW. Social media and the medical profession. Med J Aust 2011; 194: 642-644.

20. Cain J. Social media in health care: the case for organizational policy and employee education. Am J Health Syst Pharm 2011; 68: 1036-1040. 
Appendix 1. Names of Universities

\begin{tabular}{|c|c|c|}
\hline No. & Name of university & Abbreviation \\
\hline 1 & Umm Al-Qura University & UQU \\
\hline 2 & North Border University & NBU \\
\hline 3 & King Abdulaziz University & $\mathrm{KAU}$ \\
\hline 4 & Taif University & TU \\
\hline 5 & King Faisal University & KFU \\
\hline 6 & University of Tabuk & UT \\
\hline 7 & King Saud bin Abdulaziz University for Health Sciences & KSAU-HS \\
\hline 8 & Qassim University & QU \\
\hline 9 & Ibn Sina National College for Medical Studies & ISNC \\
\hline 10 & King Khalid University & KKU \\
\hline 11 & Jazan University & JU \\
\hline 12 & Princess Nora bint Abdul Rahman University & PNU \\
\hline 13 & Al-Imam Islamic University & IMAM U \\
\hline 14 & Taibah University & TAIBAH U \\
\hline 15 & King Saud University & KSU \\
\hline 16 & University of Dammam & DMU \\
\hline 17 & Salman Bin Abdulaziz University & SAU \\
\hline 18 & Unaizah College of Medicine & UNAIZAHUM \\
\hline 19 & Albaha University & BU \\
\hline 20 & Alfaisal University & ALFAISAL U \\
\hline 21 & Almaarefa College & MCST \\
\hline 22 & University of Hail & $\mathrm{UOH}$ \\
\hline 23 & Batterjee Medical College & BMC \\
\hline
\end{tabular}


Appendix 2. Research Questionnaire

- First page

1. Gender ?

C Male

C Female

2. Which medical year?

C 1st medlcal year

$C$ 2nd medlcal year

C. 3ra medlcal year

$C$ 4th medical year

C. Sth medical year

C 6th medcal year

3. Name of university ?

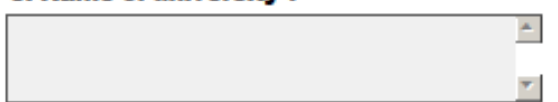

4. Do you use social media in your education ?

C Yes

C No 
- Second page

\section{How frequent do you use social media for your learning?}

C weekly

C. Twice a week

C. Three tmes a week

C Dally

other (please spedity)

6. Which of the following social media you are using in your education ?
$\ulcorner$ Youtube
$\ulcorner$ wivis
$\ulcorner$ Facebook
$\ulcorner$ Google+
$\ulcorner$ Twitter
$\ulcorner$ Blogs
ᄃ skype
$\ulcorner$ Forums

others

7. Which one you are using most ?

C Youtube

C Facebook

C. Twitter

C skype

C. Wikls

C Googlet

$C$ Blogs

C Fonms

other (please spedity)

8. How does social media affect your education?

Cholce of the drop-list Benencial

9. Does it help in relating basic to clinical science ?

C strongly Disagree

C Disagree

C Undecided

c Agree

C Strongly Agree 
- Third page

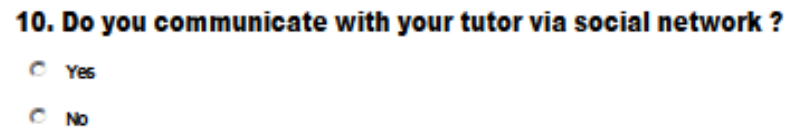

11. Does the tutor utilizes social media in education effectively ?

C strongly Disagree

C Dlsagree

C Undecided

c Agree

C Strongly Agree

12. Does your institution use social media ?

c Yes

C No

13. Does social media facilitate communication with your colleagues in your collage?

C strongly Disagree

C Dlsagree

C Undecided

C Agree

C Strongly Agree

14. Does social media facilitate communication with colleagues in other universities ?

C strongly Disagree

C Dlsagree

C Undecided

C Agree

C strongly Agree

15. Communicating with my colleagues help me to learn more about the topic?

C strongly Disagree

C Dlsagree

C Undecided

$C$ Agree

C Strongly Agree 
- Fourth page

16. Communicating with my colleagues help me to focus my studying on the important topics in exams?

c strongly Disagree

C Dlsagree

$c$ Undecided

c Agree

C Strongly Agree

17. Are you aware of ethical guidance for using social media as medical student ?

$C$ Yes

C No

18. Do you think it is important to have ethical guidance for using social media as medical students?

C strongly Disagree

$c$ Disagree

$c$ Undecided

c Agree

C Strongly Agree

19. comments ? 